\title{
Erratum to: Effect of different halophilic microbial fermentation patterns on the volatile compound profiles and sensory properties of soy sauce moromi
}

\author{
Rui-Ying Cui • Jia Zheng $\cdot$ Chong-De Wu \\ Rong-Qing Zhou
}

Published online: 20 January 2015

(C) Springer-Verlag Berlin Heidelberg 2015

\section{Erratum to: Eur Food Res Technol (2014) 239:321-331 DOI 10.1007/s00217-014-2225-9}

Unfortunately, few references and sample numbers were wrongly published in the original article. The correct numbers are given below:

1. In Table 2, the reference numbers at the second footnote should be "Refs. [36, 37]" and not "Refs. [30, 31 ]".

2. In Table 3, the reference numbers at the last footnote should be " $[1,20,21,28,38-40]$ " and not " $[1,18,19$, $28,32-34] "$.

The online version of the original article can be found under doi:10.1007/s00217-014-2225-9.

R.-Y. Cui · J. Zheng · C.-D. Wu · R.-Q. Zhou $(\bowtie)$

Key Laboratory for Leather Chemistry and Engineering

of the Education Ministry, and College of Light Industry,

Textile and Food Engineering, Sichuan University,

Chengdu 610065, China

e-mail: rqzhou@163.com; zhourqing@scu.edu.cn

R.-Y. Cui

e-mail: ry.123@163.com

J. Zheng

e-mail: 1044537505@qq.com

C.-D. $\mathrm{Wu}$

e-mail: 396901147@qq.com

R.-Q. Zhou

National Engineering Research Center of Solid-State Brewing,

Luzhou 646000, China
3. In Table 4, the reference numbers at the first footnote should be "Refs. [29, 32, 33, 41, 42]" and not "Refs. [24-26, 35]".

4. In the second column of page 326 , the reference number in fourteenth line should read as "[7]" and not " $[7,25,26]$ ".

5. In the second column of page 326, the "A1" in line 20 should read as "A2" and "A2" in line 22 should read as "A3".

6. In the first column of page 327, the sentence starting on fourth line should read as "The total amount of volatile compounds increased by $117.66 \%$ in A2, $23.28 \%$ in A3, and $216.88 \%$ in A4".

7. In the first column of page 328 , the reference number "[30]" in line 13 should read as "[28]".

Further, few references were missed in the references section. The references with the numbers are given below:

36. Solms J, Vuataz L, Egli RH (1965) The taste of L- and D-amino acids. Experientia 21:692-694.

37. Lioe HN, Wada K, Aoki T, Yasuda M (2007) Chemical and sensory characteristics of low molecular weight fractions obtained from three types of Japanese soy sauce (shoyu)—koikuchi, tamari and shiro shoyu. Food Chem 100:1669-1677.

38. Pham AJ, Schilling MW, Yoon Y, Kamadia VV, Marshall DL (2008) Characterization of fish sauce aroma-impact compounds using GC-MS, SPME-Osme-GCO, and Stevens' power law exponents. J Food Sci 73:C268-C274.

39. Lee SM, Seo BC, Kim YS (2006) Volatile compounds in fermented and acid-hydrolyzed soy sauces. J Food Sci 71:C146-C156.

40. Fukami K, Ishiyama S, Yaguramaki H, Masuzawa T, Nabeta Y, Endo K, Shimoda M (2002) Identification 
of distinctive volatile compounds in fish sauce. J Agric Food Chem 50:5412-5416.

41. Cha YJ, Cadwallader KR (1998) Aroma-active compounds in skipjack tuna sauce. J Agric Food Chem 46:1123-1128.
42. Cullere L, Escudero A, Cacho J, Ferreira V (2004) Gas chromatography-olfactometry and chemical quantitative study of the aroma of six premium quality Spanish aged red wines. J Agric Food Chem 54:1653-1660. 